\title{
LA PRIMERA OLA PANDÉMICA EN PERSPECTIVA DE HISTORIA CONECTADA Y GLOCAL
}

THE FIRST PANDEMIC WAVE IN PERSPECTIVE OF CONNECTED AND GLOCAL HISTORY.

Celia Cristina Basconzuelo ${ }^{1}$

https://orcid.org/0000-0001-9005-7227

cbasconzuelo2003@yahoo.com.ari

Aceptado:01/12/2020

Publicado online:30/09/2021

\begin{abstract}
RESUMEN
¿Cuáles fueron las acciones que conectaron a las sociedades aún distantes entre sí, a medida que iban siendo atravesadas por el virus Covid-19? ¿Emergieron tensiones no sanitarias en el marco de la expansión de la pandemia? ¿Qué experiencias situadas de la pandemia ameritan focalizar en adaptaciones locales respecto de acciones emprendidas por los gobiernos y administraciones subnacionales? Este artículo responde a dichas preguntas mediante un análisis histórico de la pandemia provocada por la propagación del virus Covid-19. A partir de la complementación entre la perspectiva de historia conectada y la historia glocal se examinan al gunas prácticas que circularon y atravesaron de manera sincrónica las sociedades pertenecientes al mundo globalizado, se analizan algunas experiencias situadas de la pandemia y se problematiza sobre la glocalización. Finalmente, se concluye que hubo una aceleración y profundización de las prácticas virtuales de comunicación y los Estados nacionales asumieron competencias en biopolítica. Sin embargo, algunos indicadores de análisis como las políticas de cuarentena exponen los matices locales, evidencian las tensiones y fundamentan la importancia de revisitar las historias situadas de la pandemia.
\end{abstract}

Palabras clave: Pandemia - COVID-19- Historia - Conectada- Glocal

\begin{abstract}
What were the actions that connected the societies still distant from other, as they were being affected by the Covid-19 virus? Did unhealthy tensions in the context of the spread of the pandemic? What situational experiences of the pandemic merit focusing on local adaptations regarding actions undertaken by governments and subnational administrations? This article answers these questions through a historical analysis of the pandemic caused by the spread of the Covid-19 virus. From the complementation between the connected history perspective and
\end{abstract}

\footnotetext{
1 Universidad Nacional de Río Cuarto. ISTE-CONICETRepública Argentina.
} 
glocal history, some practices that circulated and crossed synchronously the societies bel onging to the globalized world are examined, some situated experiences of the pandemic are analyzed, and glocalization is discussed. Finally, it is concluded that there was an acceleration and deepening of the virtual communication practices and the nation-states assumed competencies in biopolitics. However, some analytical indicators such as quarantine policies expose local nuances and show the tensions and substantiate the importance of revisiting the situated histories of the pandemic

Keywords: Pandemic - COVID-19- History - Connected- Glocal.

\section{INTRODUCCIÓN}

La historia conectada comienza a despertar interés como perspectiva de análisis en los inicios del siglo XXI.2 Se focaliza en aquellos actores, ideas o prácticas que circulan en espacios y sociedades, cercanas o distantes y generan conexiones, de manera que un mismo fenómeno adquiere dimensiones policéntricas. (Chartier, 2001; Robertson, 2003; Bertrand, 2015; Subrahmanyam, 2020) Se interesa en la búsqueda de interrelaciones que conectan sucesos locales, regionales y globales. (Douki y Minard, 2007; Stanziani, 2018)

Desde una óptica próxima a ese campo de estudio y, a la vez, diferenciándose de la historia global3, se desenvuelve la historia glocal que, según Roger Chartier (2001), concierne a "los procesos por los cuales referencias compartidas, modelos impuestos, textos y bienes circulantes a escala planetaria son apropiados para tener sentido en un tiempo y lugares particulares" ( $p$. 123). Dicha propuesta historiográfica busca recuperar la diversidad de lolocal, aunque sin oponer lo micro con lo macro. (Carzolio, 2020)

A partir de estas consideraciones preliminares se advierte la complementariedad entre ambos enfoques y la factibilidad de su aplicación para analizar algunos aspectos del proceso histórico abierto tras el desencadenamiento de la primera ola pandémica. En esta línea se sitúa el presente artículo cuyo propósito general es analizar prácticas predominantes4- que circularon y conectaron las sociedades a escala global y, a su vez, identificar otras que se hicieron visibles en escalas locales, y por ello son constitutivas de las historias situadas de la pandemia.

En efecto, el 11 de marzo de 2020 será recordado como una fecha clave en el calendario de los eventos epidémicos contemporáneos y como el acontecimiento mundial más importante en el inicio de la segunda década del siglo XXI. Ese día, Tedros Adhanom Ghebreyesus, director general de la Organización Mundial de la Salud (en adelante OMS), anunciaba desde Ginebra que la epidemia del coronavirus Covid-19 -una nueva cepa identificada dentro del grupo, pero no

\footnotetext{
2 Bertrand (2015) atribuye al historiador Serge Gruzinski el haber empleado el término "conexiones" en la revista francesa Annales, sentando las bases de este enfoque; en tanto Coelho Prado (2011) considera que fue el historiador indio Sanjay Subrahmanyam, quien amplió su sentido y alcances. Chartier (2001) sitúa en cambio los inicios en una jornada debate que tuvo lugar en mayo de 2000 y es autor de un excelente comentario acerca del aporte de los autores en cuestión.

3 Esta corriente se ocupa de "la sincronización y el encadenamiento que registran símiles trayectorias históricas en un contexto de globalidad" (Fazio Vengoa y Fazio Vargas, 2018, p. 17). Emplea abordajes comparados. (Carzolio, 2020)

4 La noción de prácticas se inspira en los trabajos de Pierre Bourdieu (1994).
} 
detectada en humanos con anterioridad5- adquiría estatus de pandemia6. El virus ya se había expandido a escala planetaria, acelerado por las dinámicas de la movilidad de personas en un mundo global interconectado.

Mientras las investigaciones emprendidas por organismos internacionales buscaban afanosamente desentrañar -y aún hoy continúan- el origen del virus, aunque los datos más evidentes lo sitúan en la ciudad china de Wuhan,7 los estudios científicos avanza ban en diversas líneas. En el campo de las ciencias sociales, ese acontecimiento histórico despertó interés de inmediato y comenzaron a producirse ensayos, artículos y publicaciones de distinto impacto y alcance temático.

Rápidamente se reflexionó sobre los evidentes trastornos que acaecían en un mundo atravesado por la globalización (Agamben, Zizek y et al., 2020), las tensiones en el sistema capitalista (Harvey, 2020); las conexiones entre pandemias y capitalismo, indicándose las consecuencias ambientales y el manejo de los ecosistemas (Molano Camargo, 2020); así como los efectos sociales de la virtualidad y el impacto de las herramientas comunicacionales (Morero, 2020; Salvat Matinrey y Aranda Martínez, 2020; Benavent, Castelló y Valderrama, 2020). Estuvieron en discusión también los retos que atravesaban las naciones latinoamericanas (Casilda Béjar, Ocampo, Alcántara, et al, 2020; Acha, 2020) y toda la comunidad internacional. (Daston, 2020) Se realizaron comparaciones con epidemias anteriores (Álvarez, 2020; López Campillay, 2020; Greif, 2020) y se trazó un cuadro imaginario acerca de cuál sería la agenda mundial post-pandémica. (Batthyány y Torres, 2020; Grimson, 2020). Algunos escritos se interrogaron acerca de la viabilidad de continuar pensando en términos globales, cuando la crisis pandémica ha revelado la importancia de las relaciones locales. (Wieviorka, 2021) Respecto de las producciones en el campo historiográfico, las mismas se expresaron acerca de las diferencias y similitudes con otras pandemias (Barona, 2020; Martínez y Cucunuba, 2021), las políticas de cuarentena (Ortuño Arregui, 2020) y la focalización en algunas grandes epidemias (Kreibohm, P. (2020), entre otras.

El listado de producciones es cada día más creciente. Centros de estudios internacionales, como L'ecole des Hautes Études en Sciences Sociales contienen páginas específicas donde se recogen las investigaciones nacionales y globales. 8 La propia OMS, en su sitio oficial, aloja una sección especial dedicada a seguir la evolución del virus, y en ese marco un área remite al continente americano.9 Del mismo modo, en Argentina, el CONICET contiene un sitio especial con las producciones que sobre el tema han realizado investigadores y becarios en el transcurso de estos dos años.10

Sin embargo, no se advierte en todo el campo de la producción histórica un abordaje de la Covid-19 desde la perspectiva de la historia conectada y en complementariedad con el enfoque

\footnotetext{
${ }^{5}$ Según la OMS "los coronavirus (CoV) son una amplia familia de virus que pueden causar diversas afecciones, desde el resfriado común hasta enfermedades más graves. El SARS-CoV-2 es el virus causante de la enfermedad pandémica actual. Véase Organización Mundial de la Salud. (s.f.) Coronavirus. Consultado el 20 de junio de 2020. https://www.who.intes/healthtopics/coronavirus

6 La palabra pandemia tiene su raíz etimológica del griego ("pan", todos y "demos", pueblo). De acuerdo con la RAE significa una "enfermedad epidémica que se extende a muchos países o que ataca a casi todos los individuos de una localidad o región". Véase https://dle.rae.es/pandemia

7 Véase el informe de la BBC News (9/2/2021). BBC News Mundo. (2021, 9 de febrero). Coronavirus en China: 4 datos sobre el origen de la pandemia revelados por la OMS tras su misión en Wuhan. BBC News. https://www.bbc.com/mundo/noticias56000244

8 Véase https://www.ehess.ff/fr/carnet/coronavirus

9 Véase https://www.who.intles/emergencies/diseases/novel-coronavirus-2019

10 Véase https://ri.conicetgov.ar/discover?query=covid-19
} 
glocal. Recuperando pues ambas líneas de abordaje se emprende esta investigación que comprende la primera etapa de la pandemia, enmarcada entre los meses de marzo y diciembre de 2020; es decir, des de el anuncio mundial a cargo de la OMS hasta el momento en que el Reino Unido se convirtió en el primer país en desarrollar una vacuna.

Los siguientes interrogantes encauzan el estudio en particular: ¿cuáles fueron las acciones que conectaron a las sociedades aún distantes entre sí, a medida que fueron atravesadas por el virus Covid-19? ¿Emergieron tensiones no sanitarias en el marco de la expansión de la pandemia? Por otra parte, ¿qué experiencias situadas ameritan focalizar en las acciones emprendidas por los gobiernos y administraciones subnacionales?

Para su desarrollo, el artículo se halla estructurado en tres apartados. En el primero, se describe la metodología empleada, las dimensiones de análisis e indicadores propuestos y las técnicas para el tratamiento de los datos recolectados. En el segundo, se presentan los principales resultados sobre la base de las fuentes analizadas y las entrevistas realizadas. El tercero discute las problemáticas planteadas a lo largo de tres sub apartados donde se abordan respectivamente las prácticas de la virtualidad ampliada, la resignificación del rol del Estado y las tensiones en el plano económico y social derivadas de la adopción de las políticas de cuarentena. Finalmente, se presentan las conclusiones.

\section{MATERIALES Y MÉTODOS}

Este trabajo propone una combinación de perspectivas de abordaje aproximando así la historia conectada y la historia glocal, para ser aplicadas al estudio de la primera etapa de desarrollo de la actual pandemia. En razón de este marco analítico se procedió a seleccionar dimensiones que permitieran focalizar en las conexiones entre las sociedades que se vieron afectadas por la propagación progresiva del virus, y reparar en otras que mostraban las dinámicas glolocales, sin desconocer que existen otras magnitudes de igual relevancia para su estudio.11

La primera dimensión de análisis comprende las prácticas conectadas y fue desagregada en dos indicadores: prácticas comunicacionales y resignificación del rol del Estado. La segunda dimensión trabaja en cambio con las prácticas situadas, y se concentró en aquellas acciones que en el plano de las políticas de cuarentena asumieron características diferenciadas en algunas escalas locales, situación que generó tensiones no solo en el plano económico sino también social.

Este trabajo se elaboró con un diseño y estrategia metodológica cualitativa. Las fuentes de la información fueron bibliográficas, periodísticas, informes técnicos de la CEPAL y sitios oficiales en internet. Las redes sociales (Facebook e Instagram) aportaron información secundaria. La recopilación documental se complementó con entrevistas estructuradas.12 Para éstas se tuvo en cuenta que el propósito consistía en arrojar luz sobre la situación pandémica en escalas locales, por lo que interesaba averiguar la visión de la persona entrevistada. La fase de preparación de la entrevista consistió en el diseño de un cuestionario con preguntas que atendían a las problemáticas planteadas, de manera que al recuperar la dimensión subjetiva testimonial se

\footnotetext{
11 Otras dimensiones que merecerían un estudio en profundidad y a escala local serían: el impacto del confinamiento en las cadenas globales y regionales de producción; la contracción del flujo turístico mundial; el impacto ambiental ante la disminución en el flujo de personas; la política exterior y los bloques regionales, protestas sociales, entre otras. Para el caso latinoamericano, la agenda incluye además ejes problemáticos tales como territorialización de la pobreza, agudización del desempleo, regresión 0 lentificación del crecimiento económico.

12 Para su diagramación y operatividad se siguió a Valles (2002).
} 
pudiese problematizar la experiencia situada del entrevistado/a, las notas distintivas locales y, al mismo tiempo, la percepción acerca de las interdependencias con la crisis pandémica global. Todo ello abría la posibilidad de entrever a partir de esos testimonios algunas tensiones que las fuentes documentales por su parte no ponían en evidencia.

El cuestionario comprendió de manera común preguntas introductorias (edad, profesión, características de la ciudad de residencia) y preguntas directas. Éstas se correspondían con dos áreas temáticas: 1- ¿qué herramientas comunicacionales se emplearon en su comunidad relacionadas con la pandemia? 2- En su ciudad, ¿se aplicaron medidas de cuarentena? ¿Cuáles? Fueron entrevistados cinco ciudadanos en total, todos mayores de edad, de distintas profesiones, residentes en ciudades metropolitanas e intermedias, cuidándose la representatividad de género: dos hombres y tres mujeres. El criterio del muestreo cualitativo fue recolectar testimonios de ciudadanos de países pertenecientes a los continentes donde la pandemia registró alto impacto en orden sucesivo, es decir, el Extremo Oriente asiático, Europa Occidental y América latina. Se contactó a los entrevistados a partir de una relación previa, teniendo en cuenta la amistad personal y/o académica. Los países referenciados a través de ellos fueron China, Suiza, Gran Bretaña y Brasil ya que representaron modalidades diferentes de la gestión estatal en materia epidemiológica. Respecto de los reparos éticos, todos los entrevistados consintieron la utilización de sus respuestas para este trabajo, así como la mención de sus nombres de pila en el texto.13

Los testimonios fueron recogidos manera virtual durante la primera ola pandémica, es decir, mientras se hallaba vigente la política de cuarentena, en el mes de mayo de 2020. En atención a estas restricciones de movilidad se confeccionó desde Argentina el cuestionario, se envió con antelación y se registró la entrevista mediante grabación magnetofónica. Luego, para el proceso de análisis del material recolectado se procedió a la transcripción de la grabación sonora. Finalmente, en la instancia de interpretación advertimos ideas y conceptos centrales y agrupamos aquellos que remitían a los aspectos diferenciales que nos permitieron recuperar las dimensiones situadas.

\section{RESULTADOS}

La posibilidad de un evento pandémico había sido planteada hace unos años atrás en ocasión de celebrarse foros internacionales dedicados a analizar la situación epidemiológica mundial. 14 Sin embargo, resultaba impensable la rapidez que podía alcanzar su propagación en un mundo interconectado a escala global. Un conjunto de científicos advirtió en la revista Lancet acerca del evento, el 30 de enero de 2020 a través de un artículo de autoría colectiva, firmado por 29 investigadores chinos. Allí se presentaban los resultados de un estudio realizado a un grupo de

\footnotetext{
13 Los entrevistados fueron Sergio (20 años), comerciante, hijo de padre chino y madre argentina, residente en Argentina quien visitó la ciudad de Fuzhou (China) al iniciarse la fiesta del Año Nuevo en ese país. Luciana (49 años), es administrativa contable en la ciudad suiza de Neuchâtel. María de los Ángeles (55 años), traductora de francés, reside en la ciudad de Leeds, en la zona norte de Inglaterra. Agripino (42 años), profesor universitario, reside en la ciudad de Salvador de Bahía, Brasil. Finalmente, Patricia, médica, 55 años, habita en la ciudad capital de Montevideo, Uruguay.

14 En el 2016, la Comisión sobre el Marco Global de Riesgos de Salud para el Futuro (GHRF) pronosticó que el mundo se enfrentaría a cuatro pandemias o más en los próximos 100 años. En el 2018, la OMS alertó del próximo advenimiento de la enfermedad $X$, una patología causada por un virus todavía no identificado que podría provocar la siguiente gran epidemia . Véase Raffio, V. (2020, 28 de marzo). Coronavirus: una pandemia anunciada pero impredecible. El periódico. https://www.elperiodico.com/es/ciencia/20200328/se-podria-haber-previsto-pandemia-coronavirus-7907323
} 
pacientes ingresados en un hospital de la ciudad de Wuhan, capital de la provincia de Hubei, en la República Popular China.15

Entre el anuncio de la pandemia y el hallazgo de la primera vacuna contra el Covid-19 transcurrió poco menos de un año. En efecto, en coincidencia con la fecha de la publicación de Lancet, el Comité de Emergencias de la OMS emitió una declaración pública donde se mencionaba "la existencia de un riesgo de salud pública de interés internacional".16 Pero, recién dos meses después, el 11 de marzo, el director del organismo caracterizó la situación sanitaria mundial y anunció el estado de "pandemia". En medio de su alocución expresó acerca de la novedad del virus: "Esta es la primera pandemia causada por un coronavirus"; y agregó luego, "hemos hecho un llamamiento a los país es para que adopten medidas urgentes y agresivas". Para entonces ya se reportaban 4.291 muertos y 118.000 casos presentes en 114 países.17 Epicentro de numerosas críticas por la demora en emitir la alerta mundial, así como por las recomendaciones cambiantes respecto de las medidas sanitarias, el mismo organismo comunicó el 31 de diciembre que autorizaba "para uso en emergencia" la primera vacuna de ARN mensajero contra la COVID-19, producida por Pfizer/BioNTech, a la vez que hacía un llamamiento para el acceso mundial y equitativo de ese hallazgo científico.18

La pandemia acusaba cifras diarias que se reportaban en cada país y comuna con el número de muertos, infectados y recuperados que permitieron ir construyendo curvas epidemiológicas.19El oriente asiático, el occidente europeo, el continente americano y en menor medida África se situaron como los escenarios paulatinamente alcanzados por el virus.20 En el continente antártico los registros fueron ínfimos21, menos aún en varias islas donde sus porcentuales son bajísimos, entre ellas, Islas Cook, Samoa Americana, Palau, Santa Elena, Isla de Pascua e Islas Marshall.

En ese contexto, se vio resignificado el rol del Estado en materia de biopolítica, con su intervención en un conjunto de novedosas regulaciones sociales, por lo que simultáneamente se disponían medidas de confinamiento de las personas en gran parte de las sociedades afectadas por el virus. Mientras eso acontecía una práctica comenzó a desenvolverse y extenderse a escala global que hizo de la tecnología comunicacional una herramienta para la conectividad virtual.

\footnotetext{
15 El estudio relataba un grupo reciente de casos de neumonía causado por un nuevo betacoronavirus, según se describía, datados en diciembre de 2019. Allí se reportaban las características epidemiológicas, clínicas, de laboratorio y radiológicas, incluyendo el tratamiento y resultados clínicos de esos pacientes. Se concluía que dicha infección había provocado grupos de enfermedades respiratorias graves, con ingreso en $\mathrm{UCl}$ y alta mortalidad, pero se desconocía el origen, la duración de la transmisión humana y el espectro clínico de la enfermedad. (Huang, Ch., Wang, Y., Li, X (etal). (2020).

16 Organización Mundial de la Salud. (2020, 30 de enero). Declaración sobre la segunda reunión del Comité de Emergencias del Reglamento Sanitario Internacional. https://www.who.intes/news/item/30-01-2020-statement-on-the-second-meeting-of-theinternational-health-regulations-(2005)-emergency-committee-regarding-the-outbreak-of-novel-coronavirus-(2019-ncov)

17 Organización Mundial de la Salud. (2020, 11 de marzo). Alocución de apertura del Director General de la OMS. https://www.who.int/es/director-general/speeches/detail/who-director-general-s-opening-remarks-at-the-media-briefing-on-covid19---11-march-2020

18 Organización Mundial de la Salud. (2020, 31 de diciembre). La OMS publica su primera validación para uso en emergencias de una vacuna contra la COVID-19. https://www.who.int/es/news/item/31-12-2020-who-issues-its-first-emergency-use-validation-fora-covid-19-vaccine-and-emphasizes-need-for-equitable-global-access

19 En noviembre de 2021, según datos mundiales se contabilizaron en 258 países un total de 252.482 .230 casos, con 5.093 .076 muertos $(2 \%)$ y 226.709 .267 recuperados $(90,5 \%)$. Véase htps://www.trtnet tr/espanol/covid19

20 Inicialmente el continente africano se vio menos afectado que Europa o América. Véase editorial de Diario Perfil. (2020, 9 de octubre). El mundo se pregunta por qué el coronavirus no fue una tragedia en África. https://www.perfil.com/noticias/coronavirus/mundopregunta-por-que-coronavirus-no-fue-tragedia-africa.phtml

21 El 22 de diciembre de 2020 se reportaron los primeros casos en la Base Chilena. Véase Montes, R. (2020, 22 de diciembre). La covid-19 llega a la Antártida. El País. https://elpais.com/sociedad/2020-12-22/la-covid-19-llega-a-la-antartida-chile-reporta-36contagios-en-una-de-sus-bases.html
} 
Rápidamente el uso de distintas plataformas impactó en distintos campos -educativo, laboral, científico, en los contactos interpersonales, etc., mientras la novedad consistía en la reconversión de la modalidad de trabajo presencial a la modalidad remota. Fue entonces su aceleración y uso intensivo la principal nota de cambio en este contexto pandémico, ya que el empleo de herramientas virtuales venía desarrollándose en las sociedades contemporáneas desde hace décadas.

Si bien estos aspectos fueron compartidos por la mayoría de las sociedades afectadas por el virus, la complementación con el enfoque de la historia glocal mostró, en base a las entrevistas, la prevalencia de matices diferenciados particularmente en materia de políticas de cuarentena. Por una parte, la gestión de la información sobre el virus y la prevención sanitaria a cargo de los gobiernos resultó en un mapa variopinto de estrategias comunicacionales, aunque convergentes en el punto de crear una representación sobre la pandemia. Por otro lado, la opción por aplicar o no las cuarentenas, y las modalidades en su intensidad adquirieron color local, en la medida que algunas prácticas aludían al empleo de herramientas de control sanitario para evitar la propagación del virus, y en este punto también se abrió un arco de situaciones diferentes entre políticas más propiciadoras de la libertad de tránsito que otras, mientras en otros lugares del planeta se desalentaba cualquier política de confinamiento.

Esta lectura de lo peculiar podría interpretarse en tiempo presente y atribuirlo a decisiones políticas frente a la emergencia sanitaria o al mismo tiempo reparar en una clave histórica y de ese modo concluir que esos matices escalares descansaban en las dinámicas políticas y societales construidas en el tiempo. En efecto, esas historias situadas de la pandemia se explicaban a partir de la pervivencia de tradiciones culturales, legados participativos, actitudes cívicas, perfiles político-ideológicos de los elencos gobernantes y características económicas y sociales estructurales. Cada una de estas dimensiones resultó interpelada por la crisis pandémica; de manera que las prácticas novedosas de la virtualidad extendida o bien la gestión estatal acentuada en materia sanitaria encontraron límites o márgenes más amplios de acción como así también de resultados, conforme no solo el avance o regresión de las cifras epidemiológicas de cada escala, sino también en relación con la trayectoria histórica previa de cada sociedad. Todo ello contribuye a delimitar un campo de problemas que demuestra la acertada opción metodológica por articular un enfoque conectado y la perspectiva glocal para el estudio de la pandemia desatada en el año 2020, que aún continúa.

\section{DISCUSIÓN}

La virtualidad conectada y la experiencia situada

La primera fase de la pandemia se desenvolvió durante la primavera del hemisferio norte y el otoño del hemisferio sur. Entre marzo y abril de 2020 la mayor parte de los países aplicaron entre marzo y abril una política sanitaria que significó colocar a las poblaciones en "cuarentena"; una palabra que rememoraba otros tiempos pandémicos y evocaba concretamente un "método de aislamiento de individuos o comunidades para frenar los contagios" (Ortuño Arregui, 2020, p. 26). 
En ese contexto se produjo una repentina aceleración en el uso de la tecnología virtual.22 Así, la sociedad poscapitalista que algunos imaginaron en los años noventa, dominada por el conocimiento, donde las relaciones interpersonales y sociales estarían atravesadas fuertemente por la virtualidad en tiempo real (Drucker, 1999), arribó repentinamente. Los recursos tecnológicos experimentaron, en efecto, un uso intensivo, mientras las acciones financieras de los creadores de sitios y plataformas por entonces más empleadas cotizaban fuertemente en las principales bolsas del mundo.23 El uso de las redes, las aplicaciones, la robótica, las tecnologías de avanzada, la inteligencia artificial, se intensificaron y mostraron a escala planetaria la posibilidad de una interacción en sincronía temporal, aunque mediados por la distancia espacial. Las informaciones que circulaban a nivel mundial permitían contar con un registro diario de las víctimas del virus y asimismo obtener un conocimiento anticipado de las lógicas del virus, lo cual hizo posible entre otros aspectos, que los países del hemisferio sur pudiesen contar con un panorama de la situación cuando ésta ya había avanzado significativamente en el hemisferio norte.

Con sorprendente rapidez, esas prácticas que conectaban a las personas en tiempo real se impusieron tanto en el mercado de trabajo como en el ámbito educativo ya que los primeros estudios científicos señalaban que la clave de la propagación del virus estaba en la circulación de las personas. Tanto en el plano laboral como educacional se venía aplicando la interacción virtual, mediada por el uso de tecnologías de avanzada24, aunque sin ese ritmo de aceleración e intensificación que se vio durante el tiempo pandémico. El teletrabajo fue aconsejadoy adoptado en muchos países como una estrategia, además, para disminuir las cifras de contagios al suspender el encuentro interpersonal en los lugares de trabajo. En el sistema educativo también se optó por la educación virtual en todos sus niveles y con el mismo propósito.

Así, la "sociedad red" de la que hablara Manuel Castells (1996), aceleró la faz comunicacional a una escala y dimensión impensables. Para difundir masivamente las informaciones sanitarias básicas se recurrió a herramientas comunicacionales y a la virtualidad. La palabra y la imagen dieron forma a una infografía que circuló en Oriente y Occidente, mediante carteles y flyers, particularmente en los espacios públicos y en los medios de comunicación. En occidente, y en los más diversos idiomas, se vio un discurso común donde resultaba interpelado el individuo, de quien se esperaba una acción personal en coherencia con el contexto de aislamiento inicial. Así, cobraron visibilidad pública expresiones emblemáticas: "Quedate en casa", "Reste á la maison", "Fique em casa", etc. Las estadísticas actualizadas fueron parte de las narrativas cotidianas acerca de la evolución de la epidemia en cada país y en todo el planeta.

Ahora bien, cabe preguntarse si en algunas sociedades la logística comunicacional que atendía el amplio arco temático comprendido por la pandemia, des de la prevención en materia sanitaria, las habilitaciones y prohibiciones hasta la explicación de las medidas gubernamentales adoptadas, mostró una mayor intensificación. En tal caso, ¿cómo lo percibieron sus ciudadanos? La respuesta nos ubica en el continente europeo donde los casos iniciales, aunque escasos, se reportaron en Francia 25 y Alemania, mientras un importante brote se registró en el norte de

\footnotetext{
22 Véase esta tesis en Angulo, M. (2020, 17 de marzo). Virtualidad, la apuesta de escuelas y universidades ante el brote de Covid19. France24. https://www.france24.com/es/20200317-coronavirus-educaci\% C3\% B3n-virtual-pandemia-solu ciones

23 Véase el artículo de Klebnikov, S. (2020, 2 de setiembre). Zoom informa ingresos espectaculares y sus acciones se disparan 40\%. Forbes Staff. https://forbes.co/2020/09/02/negocios/zoom-informa-ingresos-espectaculares-y-sus-acciones-se-disparan-40/ 24 Véase, por ejemplo, el estudio realizado en la Fundación Católica Universitaria del Norte, Colombia, en el año 2012: Sánchez Upegui, Puerta Gil y Sánchez Ceballos (2012).

25 Véase https://www.elmundo.es/ciencia-y-salud/salud/2020/02/15/5e 47c7 cefdddff/d8b 8b45fo.html
} 
Italia hacia fines de febrero de 202026 y cuando en China la tendencia comenzaba a mejorar, particularmente desde el mes de marzo.

Nuestra entrevistada residente en la ciudad suiza de Neuchâtel, comenta al respecto: "Se hicieron afiches que iban cambiando de color según el período de gravedad y tenían recomendaciones e indicaciones para que los ciudadanos supieran cómo protegerse; se colocaban en todos los transportes públicos". Por su parte, nuestra entrevistada de la ciudad de Leeds recuerda: "Todos los días, a las cinco de la tarde, había una conferencia de prensa con Boris Johnson, el ministro de salud, médicos y los encargados de la logística (...) Los anuncios explicaban las razones del porqué de este encierro"; y recalca además "al final de cada una de esas informaciones siempre había una conferencia de prensa".

Estas experiencias y el análisis de las portadas y notas periodísticas de esa etapa inicial pandémica sugieren que, si bien la información sobre el nuevo virus se instaló socialmente y los medios oficiales amplificaron espacios cedidos a tal fin, los recursos comunicacionales ganaron en complejidad y variedad ocupando más intensivamente el espacio público societal en algunas sociedades más que en otras, con un interés por llegar a la ciudadanía mediante mensajes precisos, ilustrativos y educativos. Cabe agregar que en esas ciudades del mapa europeo el transporte público es masivamente utilizado por quienes se desplazan hacia sus lugares de trabajo.

El análisis de la experiencia de la virtualidad amerita, por su parte, considerar también los matices locales. Las desigualdades entre las sociedades más altamente desarrolladas y tecnologizadas frente a las emergentes se hicieron tangibles. En América latina, al interior de las propias fronteras nacionales, se visibilizaron notorias asimetrías entre los habitantes de megaciudades y aquellos residentes en pequeñas ciudades o en comarcas rurales aisladas donde es limitado o bien inexistente el acceso a internet, por lo que se dificulta el uso de plataformas y dis positivos tecnológicos digitales. (Ziegler, Arias Segura, Bosio y Camacho, 2020; Bobadilla, Miño Vargas y Rago, 2020).

Esas brechas digitales, ya existentes, aunque profundizadas por la pandemia, incidieron en el modo diferencial que se desenvolvió el teletrabajo, con rápida adaptabilidad en las sociedades altamente desarrolladas, mientras en los países emergentes primero debieron diseñarse los dispositivos jurídicos.27 (Weller, 2020) Precisamente, en su Informe especial de 26 de agosto de 2020, la CEPAL examinaba el papel clave de las tecnologías digitales durante la pandemia y ya comentaba acerca de la situación diferencial entre los países de la región y al interior de los mismos respecto del acceso y velocidad de las redes. El documento final proponía "medidas en el área de la conectividad y la economía digital para una reactivación inclusiva". 28

\section{El retorno del Estado desde la experiencia situada}

Ante el avance del virus y frente a la urgencia de dar respuestas inmediatas a la situación pandémica desde la escala nacional, el Estado se posicionó -en general- como actor central mostrando una enérgica capacidad para gestionar políticas de salud pública. Este relanzamiento

\footnotetext{
26 Véase https://www.corriere.it/cronache/20 gennaio 30/coronavirus-italia-corona-9d6dc436-4343-11ea-bdc8faf1 $56 \mathrm{f} 19 \mathrm{~b} 7 . \mathrm{shtml}$
}

27 En Argentina, el Congreso sancionó la ley 27555 que estableció el régimen legal del contrato de teletrabajo y de acuerdo con el cual se reguló dicha modalidad, principalmente en las actividades que desempeñan funcionarios de la administración pública. 28 Véase https://www.cepal.org/es/publicaciones/45938-universalizar-acceso-tecnologias-digitales-enfrentar-efectos-covid-19 
del rol del Estado tensionaba con una de las lógicas del capitalismo y la globalización, en cuyo marco otros actores venían ocupando posiciones relevantes como el mercado, las corporaciones, las multinacionales, etc.

En este sentido, una atención especial merecía los discursos políticos presidenciales. Aún con sus matices locales, focalizaron en la dimensión gerencial de los Estados frente al virus, en su compromiso con la salud pública, en la valorización de sus agentes.29 En razón de las facultades asumidas, se habló de un "Estado de excepción" (Agamben, Zizek, Nancy, et. al, 2020), lo cual se volvió tendencia inclusive en países con sistemas democráticos y regímenes parlamentarios consolidados.

Ese tipo de Estado, según Agambem (2003), creaba las condiciones jurídicas para que el poder político ordenara la vida de los ciudadanos. La política sanitaria aconsejada y adoptada por muchos países fue la cuarentena, aunque en este aspecto hubo diversos de grados de aplicabilidad. Mientras algunos gobiernos las adoptaron rápidamente e implementaron confinamientos estrictos, otros permitieron ciertas movilidades, en tanto unos pocos optaron por evitarlas en esta primera fase de la pandemia. En estos últimos se habló de practicar "el aislamiento inteligente".30

Una vez en marcha la política de cuarentena, las libertades individuales, los derechos constitucionales como el de trabajar y circular libremente dentro de las fronteras de cada país, y el funcionamiento pleno y presencial de los poderes republicanos, vivieron un paréntesis. Controles múltiples, a cargo de fuerzas policiales nacionales o comunales, entes municipales de control, o del propio ejército poblaron las calles, creando así postales urbanas inéditas y de contraste con los tiempos democráticos normales. Se vieron tensionadas así las ideas de seguridad sanitaria individual y colectiva frente a la libertad y propiedad. Los Estados cerraron sus fronteras nacionales en una decisión inusual y no registrada desde la Segunda Guerra Mundial. La política se trasladó al interior de algunos de ellos, inclusive, de manera que se interrumpió la circulación del transporte y de las personas. Asimismo, se abrió un paréntesis en la cooperación internacional, al punto que los científicos debatieron sobre las tensiones a las que estuvieron sometidas las relaciones multilaterales cuando dominaron la escena las respuestas nacionales.31

Ahora bien, esa experiencia ¿cómo se vivió en Oriente y en Occidente? En la comparación de esas cuarentenas ¿pueden entreverse claves históricas y dinámicas sociales específicas más allá de la situación epidémica compartida con el mundo global?

Sergio, visitó la ciudad de Fuzhou al iniciarse el Año Nuevo Chino. Allí, en la capital de la provincia de Fujian, con características de ciudad costera, altamente industrializada y con una población de 7,2 millones de habitantes, vivió la experiencia de la pandemia y la aplicación de la cuarentena. En sus palabras:

\footnotetext{
${ }^{29}$ Véanse dos trabajos de referencia sobre discursos presidenciales. En un caso, se analizan de modo comparativo las estrategias y funciones en el discurso de los presidentes de Argentina y Brasil (De Camargo y Canavire, 2020); en el otro, los discursos de los presidentes de España, Francia e Italia (Pérez Tornero, Marín Lladó y Cervi(2021).

30 En Países Bajos, Alemania, Suecia, Estados Unidos, Singapur y Corea del Sur se sugirió el aislamiento para la franja etaria más vulnerable, no se permitían reuniones ni eventos y, aunque se aconsejaba quedarse en casa, se podía salir a las calles cumpliendo algunas normas, entre ellas el distanciamiento social. Véase https://www.eltiempo.com/mundo/masregiones/aislamiento-inteligente-que-paises-no-han-confinado-a-la-poblacion-482400
}

31 Véase un análisis de cómo se gestionó la pandemia en cada país de la Unión Europea y las problemáticas planteadas para este bloque regional en Álvarez y Cabeza (2020). 
La cuarentena comenzó el día 24 de enero. En la ciudad donde estábamos, a diferencia de lo que se vio en la provincia de Hubei, teníamos una cuarentena flexibilizada que nos permitía viajar dentro de la misma provincia, no se podía viajar a otra, pero si dentro de la misma; se podía ir en auto sin necesitar permisos. Lo primordial que se pidió fue el uso del barbijo quirúrgico. Y la gente respetó muchísimo todo eso, también el tema del distanciamiento social, ni las reuniones sociales, ni reunirse en los parques. Es más, hubo un tiempo, un período de unos 25 días en los que los parques se cerraron, los lugares turísticos también, pero se podía andar por la calle sin la necesidad de que fuesen días pares o impares. Se controlaba mucho el tema de la temperatura; en los barrios ocurría que cuando uno volvía a ingresar se controlaba si estaba bien, también en los supermercados y en todos los locales donde uno iba se medía el control de la temperatura.

Luciana, reside en la ciudad de Neuchâtel, Suiza, donde la administración, la agricultura y la relojería marcan la dinámica económica, a la vez que cuenta con una universidad, mientras alberga 33.489 habitantes y dista $36 \mathrm{~km}$. de Berna, la capital de la Confederación de Cantones. Acerca de esos meses álgidos de la pandemia comenta:

En toda Suiza hubo cuarentena. Pero en ningún momento fue obligatorio porque aquí no está en la constitución del país y por eso no se podía imponer. Entonces las autoridades sugirieron que las personas permanecieran en sus casas. Comenzó primero con los asilos, y ahí se cortaron las visitas de los parientes; después suspendieron las clases (...) Funcionaban los supermercados, farmacias, hospitales y atenciones de urgencia, también veterinarias, garajes, mecánicos; todas las personas que trabajaban en la construcción civil y en las calles continuaron trabajando, pero los negocios, restaurantes y cines fueron cerrados (...) Nadie tenía prohibido salir a la calle, estaba aconsejado no hacerlo y las personas realmente siguieron la regla. Cuando salían era para hacer compras, pero nunca se precisó autorización ninguna. Todas las manifestaciones y las actividades de verano, así como las fiestas nacionales y las fiestas regionales fueron canceladas. Fue creado también un programa de rastreo que se podía bajar al celular. El uso de mascarilla era obligatorio, pero solo en el transporte público y en algunos cantones se pedía el uso de mascarillas para ingresar, también en algunos establecimientos y tiendas, pero eso era en unas pocas ciudades.

En el Reino Unido la aplicación de la política de cuarentena fue más tardía, pues inicialmente se promovió el aislamiento inteligente. ¿Cómo se vivió en la ciudad de Leeds, que alberga una población de 789.194 habitantes y donde la economía está dominada por el sector de servicios? María de los Ángeles relata:

Aquí se tuvo la sensación que se cerró más tarde. Primero, a mediados de marzo, se pidió a la gente que trataran de disminuir las salidas, que las personas mayores de 70 años se quedarán sus casas. Recién se cerró oficialmente el 23 de marzo cuando ya había algunos casos. Ese día fue el primer anuncio de Boris Johnson que por 3 semanas se iniciaba una cuarentena y se dejaba abierto sólo lo necesario como los comercios de proximidad. En las oficinas se pedía que se hiciera el teletrabajo. Esa situación después fue extendida por 3 semanas más, ya que durante los primeros días de abril fue cuando comenzó el pico. La actitud del gobierno cambió bastante cuando Boris Johnson se enfermó, pero a diferencia de otros países se respetaron las libertades. Otro detalle importante es que aquí se apeló a la responsabilidad de todos, pero no hubo como en el caso de Francia o de Argentina ningún tipo de permiso o papeles que se exigiera a los ciudadanos, nunca vi que se 
detuviera a nadie ni que se le aplicarán multas ni nada. En eso se respetó bastante el tema de la libertad.

Estos relatos que nos ubican en tres escenarios locales, en un caso se corresponde con la realidad de un país comunista, en el otro autónomo y en el otro todavía perteneciente a la Comunidad Europea, la cuarentena fue aplicada de manera diferente. Las características de los regímenes políticos, las tradiciones culturales y la disponibilidad de recursos estatales para emprender campañas de concientización son dimensiones importantes para explicar esos contrastes. En efecto, no fue lo mismo la vivencia de la cuarentena en sociedades donde se aplicaron métodos de vigilancia digital, como el caso chino y en coherencia con un modelo de Estado gobernado por partido único, frente a aquellas situaciones donde una cultura cívica fundada históricamente en la preservación y defensa de las libertades individuales y la insistencia en la responsabilidad ciudadana sopesaron los controles y las disposiciones estatales, como en los casos suizo y británico. No es objeto de este artículo evaluar los impactos en cifras de estas políticas, un tema importante sin embargo para la historia demográfica y que merecería ser abordado no solo teniendo en cuenta esta primera fase pandémica, sino las sucesivos ciclos con el propósito de interpretar más ajustadamente en qué medida ese comportamiento ciudadano se proyectó en cifras promedio comparativamente aceptables, o bien despertaron una enorme preocupación en los respectivos equipos gubernamentales al punto de aplicar otras políticas como la exigencia de los pases sanitarios.

El panorama en América del Sur fue más complejo. La muestra de dos testimonios no solo a realidades contrapuestas sino el funcionamiento del sistema federal en países con esa tradición. Brasil mostró la diversidad de políticas. Agripino, explica cómo se vivó en Salvador de Bahía, ciudad metropolitana con una población de 2.948 .733 habitantes y con fuertes contrastes sociales:

Aquí tuvimos la adopción de medidas de cuarentena. La primera característica es que fueron tomadas de manera regional por los gobiernos de los Estados, cómo se vio en Bahía, Río de Janeiro, San Pablo. Cada Estado y las prefecturas, es decir, los gobiernos locales adoptaron sus medidas, porque el gobierno federal no adoptó medidas en ese sentido. El gobierno se mostró contrario a las medidas de cuarentena y de aislamiento social. Las medidas se caracterizaron también por el cierre de los espacios públicos, como plazas y playas, y de actividades consideradas no es enciales. Nos otros tuvimos la suspensión de las atenciones al público, pero sin perjuicio de las entregas por lo que se desarrolló mucho el delivery. Otra característica fue la restricción de las movilidades en la circulación urbana y regional y en el escenario nacional con medidas específicas para el uso del transporte público. La actividad turística tuvo un impacto muy negativo. También hubo una interrupción de los ómnibus intermunicipales y eso es importante destacarlo porque hay muchos municipios que dependen de otras ciudades para proveerse de servicios y de productos principales que se vieron muy afectadas.

Uruguay fue un país señalado por la singularidad de la política oficial en materia sanitaria. Patricia, residente en Montevideo explica cómo se implementaron allí las medidas:

Aquí en Uruguay hubo cuarentena, pero no obligatoria. Las características fueron principalmente distanciamiento social, uso de tapabocas, lavado de manos y evitar reuniones. Tuvo mucho que ver la responsabilidad de la población y también ayudó que la densidad de la población es baja. Hubo también ayuda económica para la gente con bajos recursos y los dirigentes políticos (senadores, diputados y poder ejecutivo) se bajaron el 
sueldo. En julio empezaron las clases de primaria y secundaria y nivel universitario parcialmente. Se abrieron los centros comerciales y las actividades gastronómicas, como los hoteles, se mantuvieron con protocolos.

Este panorama puede complementarse con el caso argentino, lugar donde no se realizaron entrevistas.32 En este país rigió una cuarentena obligatoria a partir del 20 de marzo de 2020 mediante un decreto de necesidad y urgencia (DNU) dictado por el Poder Ejecutivo Nacional, $\mathrm{N}^{\circ}$ 297/2020. En sus fundamentos declaraba: "A fin de proteger la salud pública lo que constituye una obligación inalienable del Estado nacional se establece para todas las personas que habitan en el país o se encuentren en él, en forma temporaria, la medida de aislamiento social preventivo y obligatorio".33 Dicho decreto conocido por sus siglas ASPO luego se complementó con la DISPO, Distanciamiento Social Preventivo y Obligatorio, según decreto 956/2020. Mientras la primera abarcó inicialmente todo el territorio del país y se mantuvo hasta el 26 de abril, a partir de esta fecha se establecieron medidas de alcance provincial y territorial, de aislamiento o distanciamiento, según los parámetros epidemiológicos de cada lugar, y según decía en sus considerandos: "con el fin de no interrumpir el suministro de productos y servicios esenciales y también para incorporar gradualmente la realización de diversas actividades económicas y sociales en los lugares donde la evolución de la situación epidemiológica lo permitiera".34

En síntesis, mientras la cuarentena fue una acción que conectó las experiencias de millones de ciudadanos, su implementación adquirió matices escalares. Hubo políticas de estricto confinamiento como se vio en Argentina durante varios meses, semi-confinamiento como ocurrió en la mayoría de los países europeos y de confinamiento localizado como en el caso brasileño. Por cierto, cabe considerar las densidades poblacionales, pues no es lo mismo gestionar mecanismos en un país de 3,4millones (Uruguay), de 8.545 millones (Suiza), de 66.65 millones (Gran Bretaña) y de 211 millones (Brasil). Por otro lado, la instrumentación de estas medidas mostró cómo funcionó el sistema federal en América del Sur. En Argentina, el gobierno nacional inicialmente avanzó con un decreto de cumplimiento nacional y luego fue delegando a las provincias y municipios la aplicación de medidas sanitarias más convenientes según la evolución epidemiológica; en Brasil, el gobierno federal declinó toda adopción de políticas de aislamiento social y fueron los gobiernos estaduales quienes optaron o no por medidas de aislamiento.

Este conjunto de situaciones que ha interpelado al Estado nacional y daba paso a un "tiempo de lo estatal" como podríamos denominar, colocó a sus agentes ante desafíos impensables que no solo derivaron en políticas públicas sanitarias de control; también se vieron diversas acciones de apoyo, promoción o intervención al interior del área sanitaria, como lo fueron las medidas que posicionaron a las instalaciones hospitalarias públicas, y a la vez otras por fuera de este sector. En este sentido, algunos Estados se mostraron más activos que otros en alcanzar una soberanía científica-tecnológica, y gestionaron acciones más comprometidas con el desarrollo de la ciencia y la investigación aplicada35, mientras en otros fueron las universidades privadas, los

\footnotetext{
32 Es el país de residencia de la autora de este artículo, por lo que se apeló a fuentes documentales.

33 Véase https://www.boletinoficial.gob.ar/detalleAviso/primera/227042/20200320

34 Véase https://www.boletinoficial.gob.ar/detalleAviso/primera/237844/20201130

35 Por caso, Argentina donde en marzo de 2020 quedó conformada la Unidad Coronavirus COVID-19, integrada por el Ministerio de Ciencia, Tecnología e Innovación (MINCyT), por el CONICET y por la Agencia Nacional de Promoción de la Investigación, el Desarrollo Productivo y la Innovación (Agencia I+D+i). Desde este organismo se lanzó una convocatoria que estimuló proyectos asociativos de investigación en Ciencias Sociales y Humanas para la generación de nuevos conocimientos enfocados al estudio de la sociedad argentina en la pandemia y la postpandemia del COVID-19.Véase https://www.conicet.gov.ar/el-ministerio-de-
} 
institutos de investigación y los laboratorios privados quienes se mostraron más activos y recogieron los primeros resultados exitosos. Claramente se vio iniciar una carrera entre los laboratorios más prestigiosos -europeos, asiáticos- por el hallazgo de una vacuna que generase inmunidad para alrededor de 7.700 millones de habitantes, que pueblan el planeta tierra. En ese trayecto dos actores iniciales cobraron fuerte relevancia en Europa: la Universidad de Yale y la de Oxford; mientras el Instituto Gamaleya lo hacía en la Federación Rusa. Más allá de estas sensibles diferencias, un común denominador recorría el campo de la investigación: los científicos resultaron interpelados, consultados, convocados en algunos casos por equipos gubernamentales, situación que los mostró muy activos como actores sociales expertos.36

\section{Las tensiones en pandemia}

Las implicancias económicas derivadas de la implementación de políticas de cuarentena se hicieron evidentes a escala planetaria. En líneas generales, los gobiernos se vieron tensionados entre responder a la dinámica del capitalismo -que en términos operativos significaba mantener activa la economía básica y el consumo-, adoptar estrategias para mantener los sistemas sanitarios públicos en disponibilidad y al mismo tiempo monitorear las fluctuaciones en las pirámides demográficas que -cotidianamente en el orden mundial- daban cuenta de las cifras que el virus se cobraba contabilizando muertos, contagiados y recuperados.

En torno a este eje temático, las historias situadas de la pandemia muestran escenarios no solo diferenciales sino además asimétricos, por lo que deben considerarse los matices locales. ¿Cómo se vivió ese proceso en los países donde realizamos las entrevistas? En Suiza, nuestra entrevistada comenta:

Aquí se promovió el teletrabajo. Pero, en el caso de aquellas personas que tenían sus empleos en empresas más pequeñas como restaurantes, bares, salones de belleza y negocios, como estaban cerrados, el Estado se responsabilizó por el pago de ese salario. Entonces esos empleados fueron colocados a través de un seguro de desempleo (chomage tecnique) que sería sólo para ese período. Las fronteras con Francia, Alemania e Italia fueron cerradas, pero a las personas que trabajaban del lado italiano, por ejemplo, el Estadose ocupó de ubicarlas en hoteles para evitar que fueran y viniesen todos los días.

La situación en Inglaterra es en parte diferente ya que enfrenta problemas de precariedad laboral, particularmente dentro del grupo de extranjeros. María de los Ángeles, residente en Leeds, comentaba:

El problema económico se vio venir porque hay mucha gente que trabaja por sucuenta, es decir, son autónomos, hay mucha precarización del trabajo que involucra sobre todo a los extranjeros que trabajan por contrato, en razón del día o por la semana. El Estado les dio a ellos la ATP, también para pequeñas empresas y todos los que lo solicitaran; se les abonaba el $80 \%$ de los sueldos y eso fue pagado regularmente. Lo que sí registró en aumento fue el banco de alimentos y personas que antes tenían sutrabajo y lo perdieron; aquí hay enorme cantidad de centros de ayuda a la gente y locales donde venden productos que son para estas ayudas. Estos centros trabajan con muchos voluntarios y

ciencia-tecnologia-e-innovacion-conformo-la-unidad-coronavirus-covid-19/;

http://www.agencia.mincyt.gob.ar/frontend/agencia/convocatoria/438

36 Una gubernamental donde se evidenció esa participación de expertos y a la vez de elencos interdisciplinares fue la de Ángela Merkel. Véase el estudio de Requena (2020). 
significa en realidad una forma de terciarizar la responsabilidad del Estado en el plano de lo social.

Estos testimonios muestran que conforme la epidemia avanzaba en las poblaciones los Estados implementaron políticas de emergencia económica y de asistencia mediante créditos orientados a sostener a las pequeñas y medianas empresas, como así también medidas paliativas para frenar el desempleo. Ese proceso -todavía se halla en curso- se explica no solo en función de las decisiones políticas, sino también en referencia a la historia económica y financiera reciente de esos países. Frente a las variables sensibles que se desestabilizaban, la mayor capacidad de maniobra de los elencos estatales dependió fuertemente de la coyuntura económica, de los índices de crecimiento y desarrollo sostenible y del estado equilibrado de las arcas fiscales previos a la situación pandémica.

Mientras en el continente europeo parecía resurgir una suerte de Estado providencia37, con matices diferenciados según las escalas nacionales, en América latina los rasgos de esa intervención estatal fueron aún más variados. Aquí la situación pandémica encontró un cuadro previo de desigualdad social, pobreza, indigencia, trabajo informal y en varios países (tal el caso de Argentina) una abultada deuda externa.

La CEPAL preveía en su informe de julio de 2020 que la tasa de desocupación regional se ubicaría alrededor del 13,5\% lo que representaba un alza de dos puntos porcentuales respecto del mes de abril, y un incremento de 5,4 puntos porcentuales respecto del valor registrado en 2019. Su pronóstico era todavía más desalentador respecto de la actividad económica, la cual interpretaba bajo un signo de contracción profundizada a causa de la pandemia con una caída de $-9,1 \%$ a lo largo de ese año.38

Algunos gobiernos aplicaron políticas sociales paliativas. En Argentina, por ejemplo, se instrumentó el Ingreso Familiar de Emergencia (IFE), por decreto del presidente Alberto Fernández, fechado el 23 de marzo de 2020.39 Se trató de un seguro social para los trabajadores informales, monotributistas sociales, personal doméstico y beneficiarios de planes sociales anteriores que se vieron imposibilitados de continuar con sus actividades debido al aislamiento social y obligatorio que decretó el gobierno diez días antes a causa de la pandemia de COVID-19. Alcanzó a nueve millones de personas.

Simultáneamente, otros actores sociales intervinieron en el escenario social pandémico. Allí donde el Estado no consiguió llegar de inmediato, vio activarse un tejido solidario de base con múltiples acciones colectivas. Hubo redes comunitarias que operaron con un mayor o menor nivel de institucionalización, como en el caso de los voluntariados, los comedores en villas de emergencia y barrios carenciados, los fondos y donaciones de distintas entidades de bien público y gremiales, así como también -en algunas ciudades- el trabajo asociativo entre las universidades públicas, los gobiernos municipales e inclusive fuerzas policiales y militares 40

Ahora bien, entre el freno de la economía y el paréntesis en el ejercicio de las libertades civiles se creó un arco de tensiones sociales que no tardaron en manifestarse en la forma clásica de las

\footnotetext{
37 El concepto pertenece al historiador francés Pierre Rosanvallon (1995) quien lo empleó para referir el papel del Estado en materia de seguridad social que se vio modificado ampliamente a partir de los años noventa.

${ }^{38}$ CEPAL. Comunicado de prensa. Consultado el 15 de julio de 2020. https://www.cepal.org/es/comunicados/contraccion-laactividad-economica-la-region-se-profundiza-causa-la-pandemia-caera-91

${ }^{39}$ Véase https://www.argentina.gob.ar/economia/medidas -economicas-COVID19/ingresofamiliardeemergencia

40 En Argentina se constituyeron los Comités Operativos de Emergencias (COE) en todas las provincias y departamentos, integrados por fuerzas armadas, de seguridad, bomberos voluntarios, defensa civil, autoridades hospitalarias, entre otras.
} 
protestas. Se enarbolaron repertorios y demandas anti-cuarentena. Por caso, los rancheros, sheriffs y políticos en el Estado de Idaho (oeste de los EEUU), 41 los 10.000 ciudadanos movilizados en Tel Aviv en contra de la política del primer ministro israelí Benjamin Netanyahu42. El 29 de agosto de 2020, miles de personas se manifestaron en Berlín, París, Copenhague y otras ciudades de Europa en contra de la cuarentena por la pandemia y el uso obligatorio de barbijos en espacios públicos, en un momento en que se registraban los rebrotes de contagios.43 Latinoamérica no fue ajena a ese escenario de protestas que cuestionaban el manejo de la crisis sanitaria.44 En Argentina, diversas marchas anti-cuarentena fueron movilizadas por activistas en las redes sociales, dirigentes de los partidos de oposición y ciudadanos disconformes por la parálisis de las actividades económicas. 45

Más allá de estos segundos actores y de la interpelación que era objeto el Estado nacional, las movilizaciones hacían visibles en el espacio público a los ciudadanos, marcando de ese modo una diferencia con otros ciclos de protestas anteriores a esa fase pandémica donde los protagonistas de las demandas fueron mayormente movimientos sociales $u$ organizaciones de la sociedad civil, lo cual amerita futuras investigaciones que focalicen en estas diversas experiencias ciudadanas contestatarias.

\section{CONCLUSIONES}

El artículo analizó un evento de la historia reciente, la primera fase de la actual pandemia, a través de la complementación entre el enfoque de historia conectada e historia glocal. En atención a ello se escogieron dos dimensiones de análisis que permitieron, por un lado, dar cuenta de prácticas conectadas y, por el otro, problematizar experiencias situadas a partir de una complementación entre fuentes documentales y entrevistas estructuradas.

Así se mostró la circulación de una idea en común: la adopción sincrónica y global de las conectividades complejas. Dicha práctica vino a acelerar, más que introducir un cambio rotundo, respecto de un proceso que caracterizaba el mundo globalizado con una trayectoria previa en materia de interconexión y aplicación de la tecnología. Lo novedoso fue su impacto en el ámbito educativo y laboral. Asimismo, cobró resignificación el rol del Estado en el área de la biopolítica como actor central y gerencial en materia de plantear estrategias para encarar la pandemia.

Sin embargo, tanto en un plano como en el otro se advirtieron matices diferenciados en el que mucho contribuyeron a explicar los testimonios recolectados y la reflexión histórica acerca de los contextos previos a la pandemia. Las escalas locales, redimensionadas, por su parte, des de el momento que las políticas de cuarentena significaron -en general- una retroversión de la vida cotidiana al ámbito familiar y al marco de la ciudad que se habitaba, mostró las magnitudes diacrónicas de los aspectos analizados. Una sociedad global interconectada y atravesada al

\footnotetext{
${ }^{41}$ Véase el clima de protestas en EEUU, https://rpp.pe/mundo/actualidad/covid-19-estados-unidos-donald-trumpprotestas-presionan-al-presidente-y-a-gobernadores-para-levantar-la-cuarentena-noticia-1259096

42 Véase https://www.france24.com/es/20200802-is rael-protesta-renuncia-netanyahu-pandemia-investigacion

43 Para el caso europeo, véase una radiografía de las protestas en https://www.elfinanciero.com.mx/mundo/protestas-en-union-europea-meten-presion-para-reducir-el-aislamientoante-crisis/

44 Para el caso latinoamericano, véase un panorama en https://www.efe.com/efe/america/sociedad/saqueosprotestas-y-choques-politicos-radiografia-del-covid-19-en-america/20000013-4223519

45 Véase entre ellas las siguientes movilizaciones, no solo en Buenos Aires sino también en el resto del país: https://argentina.as.com/argentina/2020/05/26/actualidad/1590500664 838484.html;

https://tn.com.ar/videos/politica/las -protestas-en-todo-el-pais-tucuman-mar-del-plata-rosario-y-cordoba-tambienmarcharon-el-17a_1105792/; $\quad$ https://www.clarin.com/politica/comienza-banderazo-12-gobierno-nacionaldistintos-puntos-pais 0 j0Q-04rbg.html
} 
mismo tiempo por la pandemia dejó al descubierto, sin embargo, los trayectos diferenciales y desiguales recorridos respecto del desarrollo tecnológico y digital entre sociedades altamente evolucionadas frente a las emergentes. La globalización de un mismo virus mostró, por tanto, asimetrías en la capacidad de las naciones -y pese al activo papel gestor estatal en muchas de ellas- para sostener variables económicas de gran impacto en la vida de los ciudadanos como el empleo.

El evento epidemiológico desatado en 2020 -todavía en curso- resulta de una configuración sumamente compleja. Por tanto, son las historias situadas en las múltiples escalas -locales, regionales, nacionales- las que aluden a una cartografía diversa acerca de cómo se enfrentó un mismo virus en un contexto pandémica global. Las tensiones que devinieron en ese marco y tras la "nueva normalidad" constituyen un debate todavía en ciernes.

\section{REFERENCIAS}

Acha, O. (2020). Pensar históricamente en una coyuntura de emergencia. Sociedade Brasileira de Teoria e História da Historiografia, 13(32), 11-16. https://doi.org/10.15848/hh.v13i32.1609.

Agamben, G. (2003). Estado de excepción. Adriana Hidalgo editora.

Agamben, G., Zizek, S., Nancy, J., Berardi, F. et al. (2020). Sopa de Wuan. Aspo. https://www.elextremosur.com/files/content/23/23684/sopa-de-wuhan.pdf.

Álvarez, A. (2020). La historia del Covid19 en tiempos del Coronavirus. Un ensayo inconcluso. Pasado Abierto, 1(11), 213-235. https://fh.mdp.edu.ar/revistas/index.php/pasadoabierto/article/view/4215/4258.

Álvarez, M. V. y Cabeza, M. (2020) La Unión Europea y el Covid-19: pandemia global, respuestas nacionales ¿soluciones europeas?

GEUE. https://rephip.unr.edu.ar/bitstrea m/handle/2133/19075/Dossier\%20UE\%20COVID19.pdf?se quence $=3$ \&isAllowed $=y$

Batthyány, K. y Torres, E. (Coords.). (2020). La crisis mundial del Covid-19: sociologías, feminismos y sociedad mundial. Astrolabio. Nueva época, 25(1), 1-8 https://revistas.unc.edu.ar/index.php/astrolabio/issue/view/2096.

Barona, J. L. (2020). Tiempo de pandemia: una reflexión desde la historia. Métode, 105, 96-97. https://metode.es/wp-content/uploads/2020/05/105ES-historias-ciencia-tiempopandemia.pdf

Benavent, R., Castelló, L. y Valderrama, C. (2020). Información y comunicación durante los primeros meses de Covid-19. Infodemia, desinformación y papel de los profesionales de la información. Profesional de la información, 29(4), 1-17. http://profesionaldelainformacion.com/contenidos/2020/jul/aleixandre-castellovalderrama.html

Bertrand, R. (2015). Historia global, historias conectadas: ¿un giro historiográfico?. Prohistoria, 18(24), 3-30. https://www.redalyc.org/pdf/3801/380144016001.pdf

Bobadilla, M., Miño Vargas, D. y Rago, M. (2020). Hacia una pedagogía en la virtualidad: ¿vincularidad en tiempos de pandemia? Red Sociales, 7(5), 25-34. https://ri.unlu.edu.ar/xmlui/handle/rediunlu/778

Bourdieu, P. (1994). Razones prácticas. Sobre la teoría de la acción. Anagrama.

Carzolio, M. (2020). De lo local a lo global en el espacio de las historias conectadas. Cuadernos de $\mathrm{H}$ ideas, 14(14), 1-24. https://perio.unlp.edu.ar/ojs/index.php/cps/article/view/6570 
Casilda Béjar, R., Ocampo, J., Alcántara, M., et al (Coord.). (2020). El consenso latinoamericano 2020: una nueva visión para la era postcovid-19. Documentos de Trabajo. Universidad de Salamanca. http://www.copyscyl.org/2020/07/22/el-consenso-latinoamericano-2020-unanueva-vision-para-la-era-postcovid-19-publicado-por-el-ins tituto-de-iberoamerica-de-lausal/.

Castells, M. (1996). La sociedad red: una visión global. Alianza Editorial.

Chartier, R. (2001). La conscience de la globalité (commentaire). Annales. Histoire, Sciences Sociales, 56(1), 119-123. https://doi.org/10.3406/ahess.2001.279936

Daston, L. (2020). Empirismo de la zona cero. Calderón 094. https://critinq.wordpress.com/2020/04/10/ground-zero-empiricism/. Acceso en: 28 jun. 2020.

De Camargo, H. y Canavire, V. (2020). Análisis de discursos presidenciales en contexto de pandemia: los casos de Brasil y Argentina. En C. Alves de Araújo; A. Pereira y L. Araujo (Ed.), Os discursos de um Brasil efervescente em tempos de pandemia (pp. 76-100). Londrina, Syntagma Editores. https://ri.conicet.gov.ar/handle/11336/120168

Douki, C. y Minard, P. (2007). Histoire globale, histoires connectées: un changement d'échelle historiographique ?. Modern \& Contemporary History Review, 5(54), 7-21. https://www.cairn.info/revue-d-histoire-moderne-et-contemporaine-2007-5-page-7.htm

Drucker, $\mathrm{P}$ (1999). La sociedad poscapitalista. Editorial Sudamericana.

Fazio Vengoa, H. y Fazio Vargas, L. (2018). La historia global y la globalidad histórica $\begin{array}{llll}\text { contemporánea. Historia crítica, 3-20. } & \text { 69, }\end{array}$ https://revistas.uniandes.edu.co/doi/pdf/10.7440/histcrit69.2018.01

Greif, E. (2020). El antepasado de una pandemia: las sociedades occidentales ante la emergencia de la peste bubónica. Trabajo y Sociedad, 21(35), 151-158.

Grimson, A. (Coord.). (2020). El futuro después del Covid-19. Argentina Unida. https://www.argentina.gob.ar/sites/default/files/el_futuro_despues_del_covid-19.pdf.

Harvey, D. (2020). Política anticapitalista en tiempos de COVID-19. Herramienta. Revista de crítica y debate marxista, 62, 1-28. https://herramienta.com.ar/articulo. php?id=3166.

Huang, Ch., Wang, Y., Li, X (et.al). (2020). Clinical features of patients infected with 2019 novel coronavirus in Wuhan, China. Lancet, 395, 497-506. https://www.thelancet.com/action/showPdf?pii=S0140-6736\%2820\%2930183-5

Kreibohm, P. (2020). Tres pandemias en la historia. Relaciones Internacionales, 58, 289-294. http://sedici.unlp.edu.ar/handle/10915/102520

López Campillay, M. (2020). Ante la pandemia de covid-19: historia, microbios y olvido. Claves. Revista De Historia, 6(10), 293-299. https://ojs.fhce.edu.uy/index.php/claves/article/view/578.

Martínez M. y Cucunuba, Z. M. (2021). Conversatorio "Covid-19 y las pandemias en la historia». Historia y Memoria, (23), 337-378. https://revistas.uptc.edu.co/index.php/historia_memoria/article/view/12848

Molano Camargo, F. (2020). Capitalismo y pandemias. Traficante de sueños. https://traficantes.net/sites/default/files/pdfs/LEM13_Molano_web_0.pdf

Morero, H. (2020). La expansión de la digitalización tras la pandemia Covid19: virtualidad, vigilancia social e industria. Debates sobre Innovación, 5(1), 61-67. https://ri.conicet.gov.ar/handle/11336/131750

Ortuño Arregui, M. La historia de las pandemias y sus cuarentenas a lo largo de la historia. ArtyHum, 72 , 23-50. https://www.artyhum.com/descargas/PDF/ArtyHum\%20n\%C2\%BA\%2072.pdf\#page=24 
Pérez Tornero, J., Marín Lladó, C. y Cervi, L. (2021). Pandemia y guerra: narrativas de crisis y liderazgo. Análisis de las estrategias discursivas presidenciales en el inicio de la pandemia del Covid-19. Revista Latina de Comunicación Social, (79), 1-21. http://nuevaepoca.revistalatinacs.org/index.php/revista/article/view/895

Requena, P. (2020). Angela Merkel y cómo la gestión de la crisis de la pandemia puede marcar su $\begin{array}{llll}\text { legado. Boletín } & \text { 3EEE, 19, }\end{array}$ https://dialnet.unirioja.es/servlet/articulo?codigo=7625258

Robertson, R. (2003). Glocalización: tiempo-espacio y homogeneidad-heterogeneidad. En J.C. Monedero, Cansancio del Leviatán: problemas políticos de la mundialización (pp. 261-284). Madrid, Trotta.

Rosanvallon, P. (1995). La nueva cuestión social. Repensar el Estado providencia. Manantial.

Salvat Martinrey, G. y Aranda Martínez, S. (2020). Análisis de contenido de la prensa diaria es pañola sobre el uso de la infografía para informar de la crisis sanitaria de la Covid-19. Revista $\begin{array}{lllll}\text { de Comunicación } & \text { y } \quad \text { Salud, 185-210. }\end{array}$ http://www.revistadecomunicacionysalud.es/index.php/rcys/article/view/254

Sánchez Upegui, A., Puerta Gil, C. y Sánchez Ceballos, L. (2012). Estrategias para la interacción virtual en contextos educativos y de teletrabajo. Católica del Norte Fundación Universitaria.

Subrahmanyam, S. (2020). Historias conectadas: notas para una reconfiguración de Eurasia en la modernidad temprana. Prohistoria, 23(33), 7-34. https://ojs.rosarioconicet.gov.ar/index.php/prohistoria/article/view/1079

Stanziani, A. (2018). Les entrelacements du monde. Histoire globale, pensée globale. CNRS Éditions.

Valles, M. (2002). Entrevistas cualitativas. Centro de Investigaciones Sociológicas.

Weller, J. (2020). La pandemia del COVID-19 y su efecto en las tendencias de los mercados laborales. Naciones Unidas; CEPAL. https://repositorio.cepal.org/bitstream/handle/11362/45759/1/S2000387_es.pdf

Wieviorka, M. (2021). ¿Sigue vigente el pensar global? Revista mexicana de ciencias políticas y sociales. 66(242).https://dialnet.unirioja.es/ejemplar/576790

Ziegler, S., Arias Segura, J., Bosio, M. y Camacho, K. (2020). Conectividad rural en América latina y el Caribe: un puente al desarrollo sostenible en tiempos de pandemia. Banco Interamericano de

Desarrollo.

https://repositorio.iica.int/handle/11324/12896?utm_medium=Email\&utm_source=Comuni cado+de+prensa\%3A+EI+IICA\%2C+con+apoyo+del+BID+y+Microsoft\%2C+lanza+estudio+sob re+el+desarrollo+de+habilidades+digitales+en+la+ruralidad\& 